\title{
Combined Deformation and Solidification-Driven Porosity Formation in Aluminum Alloys
}

\author{
S. BHAGAVATH, B. CAI, R. ATWOOD, M. LI, B. GHAFFARI, P.D. LEE, \\ and S. KARAGADDE
}

In die-casting processes, the high cooling rates and pressures affect the alloy solidification and deformation behavior, and thereby impact the final mechanical properties of cast components. In this study, isothermal semi-solid compression and subsequent cooling of aluminum die-cast alloy specimens were characterized using fast synchrotron tomography. This enabled the investigation and quantification of gas and shrinkage porosity evolution during deformation and solidification. The analysis of the 4D images (3D plus time) revealed two distinct mechanisms by which porosity formed; (i) deformation-induced growth due to the enrichment of local hydrogen content by the advective hydrogen transport, as well as a pressure drop in the dilatant shear bands, and (ii) diffusion-controlled growth during the solidification. The rates of pore growth were quantified throughout the process, and a Gaussian distribution function was found to represent the variation in the pore growth rate in both regimes. Using a onedimensional diffusion model for hydrogen pore growth, the hydrogen flux required for driving pore growth during these regimes was estimated, providing a new insight into the role of advective transport associated with the deformation in the mushy region.

https://doi.org/10.1007/s11661-019-05378-8

(C) The Minerals, Metals \& Materials Society and ASM International 2019

\section{INTRODUCTION}

THE drive to improve fuel economy and reduce $\mathrm{CO}_{2}$ emissions continues to incentivize the development of low-cost lightweight high-strength cast alloys for automotive and other transport applications. ${ }^{[1]}$ These light alloys are required to possess excellent strength and fatigue properties, together with good weldability and machinability, all at a low cost. ${ }^{[1,2]}$ These properties are heavily influenced by the presence of the microstructural features and solidification defects like hot tear, ${ }^{[3,4]}$ segregation, ${ }^{[5-7]}$ and porosity, ${ }^{[8,9]}$ which exist in forms of (a) gas porosity, ${ }^{[10]}$ (b) shrinkage porosity ${ }^{[11]}$ and shrinkage bands in twin-roll and High-pressure die castings (HPDC). ${ }^{[12]}$ The nucleation of these

S. BHAGAVATH is with the Department of Mechanical Engineering, Indian Institute of Technology Bombay, Mumbai 400076, India and also with the Research Complex at Harwell, Harwell Campus, OX11 0FA, UK. B. CAI is with the School of Metallurgy and Materials, University of Birmingham, Edgbaston, Birmingham B15 2TT, UK. R. ATWOOD is with the Diamond Light Source, Harwell Campus, OX11 0DE, UK. M. LI and B. GHAFFARI are with the Ford Research and Advanced Engineering, Dearborn. P.D. LEE is with the Research Complex at Harwell and also with the University College of London, WC1E 6BT, UK. Contact e-mail: peter.lee@ucl.ac.uk S. KARAGADDE is with the Department of Mechanical Engineering, Indian Institute of Technology Bombay. Contact e-mail: s.karagadde@iitb.ac.in

Manuscript submitted April 2, 2019

Article published online August 5, 2019 solidification defects can be traced to the semi-solid state having relatively high solid fractions during the solidification. It is known that at these higher solid fractions, a network of solid is formed and as a consequence, the permeability of the mushy zone will decrease, resulting in difficulty in further feeding of the liquid. Based on the amount of fractions of solid, the solid network has been interpreted as a continuous solid skeleton ${ }^{[13,14]}$ and cohesion-less granular solid. ${ }^{[15-17]}$ The thermo-mechanical response of this network under deformation is understood to play a key role in the formation of defects.

Laboratory- and synchrotron-based semi-solid deformation tests have been extensively carried out by researchers to understand the thermo-mechanical behavior of several aluminum alloys, particularly binary $\mathrm{Al}-\mathrm{Cu}$ alloys. ${ }^{[18]}$ While tensile tests have been conducted to determine the strength and ductility of the network, ${ }^{[19]}$ shear ${ }^{[20]}$ and compression tests ${ }^{[18]}$ were used to study the rheology of the semi-solid. Tzimas et al. ${ }^{[18]}$ reported semi-solid compression tests of $\mathrm{Al}-4$ wt pct $\mathrm{Cu}$ alloys that cover the effect of solid fraction, strain rate, and grain morphology and identified different factors affecting the flow resistance ${ }^{[18]} \mathrm{Kim}$ et al., ${ }^{[21]} \mathrm{Kang}$ et al., ${ }^{[22]}$ and Kapranos et al. ${ }^{[23]}$ conducted compression experiments to study the rheological behavior of various aluminum alloys at different solid fractions and strain rates and reported liquid segregation and cracks at the edge of the specimens. The development of advanced 
synchrotron experimentation via fast X-ray techniques has allowed observations of the microstructural features during deformation in situ. ${ }^{[24,25]}$ Kareh et al., ${ }^{[26]}$ and Cai et al. ${ }^{[27]}$ reported in situ compression experiments and quantified the granular motion and dilatancy at various imposed strains. The in situ studies confirmed the role of volume dilation during tensile and compressive deformation of the semi-solid in forming defects such as hot tears and shear bands. ${ }^{[20]}$ Several theories of micromechanisms of hot tear defect formation have been proposed and criteria for cracking have been developed based on the experimental studies. ${ }^{[28,29]}$ However, most of these models do not account for the local thermal history, formation of combined gas and shrinkage porosity, and its effect on the initiation of hot cracks. Since the shrinkage and gas porosity are believed to account for about 35 pct of the total defects in highpressure die-cast components, ${ }^{[30]}$ a $3 \mathrm{D}$, real-time information of the defect formation is critical to develop predictive models for porosity and cracks at both microscopic (size and shape) and macroscopic (location and volume fraction) levels.

The diffusion-driven growth of the gas micro-porosity based on the differential solubility of hydrogen in the melt and the solid is well known in the literature. ${ }^{[31,32,33]}$ Early research on gas porosity focused on the quenching experiments and post-mortem observation of the microstructures. Lee and $\mathrm{Hunt}^{[31]}$ were the first to report the observation of porosity in $\mathrm{Al}-\mathrm{Cu}$ alloys in real-time using an X-ray temperature gradient stage, and the quantification of the cooling rate on the pore radius and the volume fractions. Subsequently, experimental studies on the hydrogen micro-porosity during directional solidification were reported by Arnberg and Mathiessen, ${ }^{[32]}$ Liao et al., ${ }^{[33]}$ and Lie et al. ${ }^{[34]}$ Catalina et $a{ }^{[35]}$ observed the change in pore shape to ellipsoid when the pore is surrounded by the solutal layer ahead of the solid-liquid interface and estimated the increase in growth rate during engulfment. Based on the X-ray radiographic observations, several empirical models of pore growth, which account for the influence of hydrogen diffusion, volumetric shrinkage, ${ }^{[36]}$ and presence of microstructural features like intermetallics, ${ }^{[37}$ have been reported. Likewise, the formation of shrinkage porosity due to lack of feeding has been reported via several experimental studies. For e.g., Gourlay et al. ${ }^{[16,20]}$ investigated the mechanism for the formation of shrinkage bands and Li et al ${ }^{[38]}$ reported the influence of melt flow and externally solidified crystals on the formation of defect bands in HPDC of AZ91D magnesium alloy.

However, the mechanisms of pore growth during deformation and purely convective conditions, and the role of liquid flow in promoting porosity growth are neither reported nor quantified, to the best of our knowledge. This information is critical to understand and develop models to predict the size and location of porosity. In this study, compression of semi-solid Al-Si$\mathrm{Cu}$ die-cast alloys, with and without modified copper content, has been performed to quantify the flow-driven pore nucleation and growth. The liquid fraction distribution and the nucleated porosity in the dilatant bands were quantified at different strain values during compression. A 1D diffusion-controlled gas porosity model was used to quantify the flux required for pore growth, which provided insights into the propensity of advective hydrogen transport in enhancing the growth of hydrogen pores. In what follows, we present the experimental methodology, analysis, and quantification of the 4D (3D + time) data characterizing the nature of deformation-induced and solidification-driven pore growth.

\section{MATERIALS AND METHODS}

Die-cast aluminum alloy ADC12 and a Modified ADC12 alloy (will be termed as MADC12 henceforth) with an additional $10 \mathrm{wt}$ pct copper were used in the study. The modified alloy was used to achieve an enhanced contrast between the primary phase and the inter-dendritic liquid. A secondary objective of modifying the alloy was to investigate the influence of the change in freezing range on hydrogen pore growth, and thus the propensity of cracking. The chemical composition of the major alloying elements (Table I) was assessed using inductively coupled plasma atomic emission spectroscopy (ICP-AES) technique.

\section{A. Sample Preparation}

Calculated amounts of ADC12 alloy and 99.99 pct copper were melted in a coreless induction furnace fitted with a pure graphite crucible lined with magnesite refractory. The molten alloy was continuously stirred for 2 minutes with a graphite rod to ensure that the alloy composition is uniform. Then the metal was poured into a cast iron die of dimension $250 \times 50 \times 40 \mathrm{~mm}^{3}$ and allowed to cool in air. The ADC12 and MADC12 alloy ingots were then machined into 3-mm-diameter cylinders using wire electrical discharge machining. The length of the final samples was $5.4 \pm 0.3 \mathrm{~mm}$. The Scheil solidification model in Thermo-Calc $\AA^{[39]}$ was used to obtain the freezing range for determining the experimental conditions, and is shown in Figure 1. The estimation of solidification range by Thermo-Calc ${ }^{\circledR}$ was validated by conducting bulk cooling experiments as shown in the inset of Figure 1. Since MADC12 has a larger freezing range, the hot-cracking propensity is expected to be higher.

\section{B. Semi-Solid Compression Experiments}

The semi-solid compression experiments were conducted at $\mathrm{I} 12$ beamline of the Diamond Light Source ${ }^{[40]}$ (beamtime reference - EE16188). A PID-controlled resistance furnace fitted with an X-ray transparent

Table I. Chemical Assay of the Alloys Under Study

\begin{tabular}{lccc}
\hline Sample & $\mathrm{Cu}$ (Wt Pct) & Fe (Wt Pct) & Si (Wt Pct) \\
\hline ADC12 & 1.82 & 0.74 & 11.9 \\
Modified ADC12 & 10.43 & 0.80 & 10.5 \\
\hline
\end{tabular}




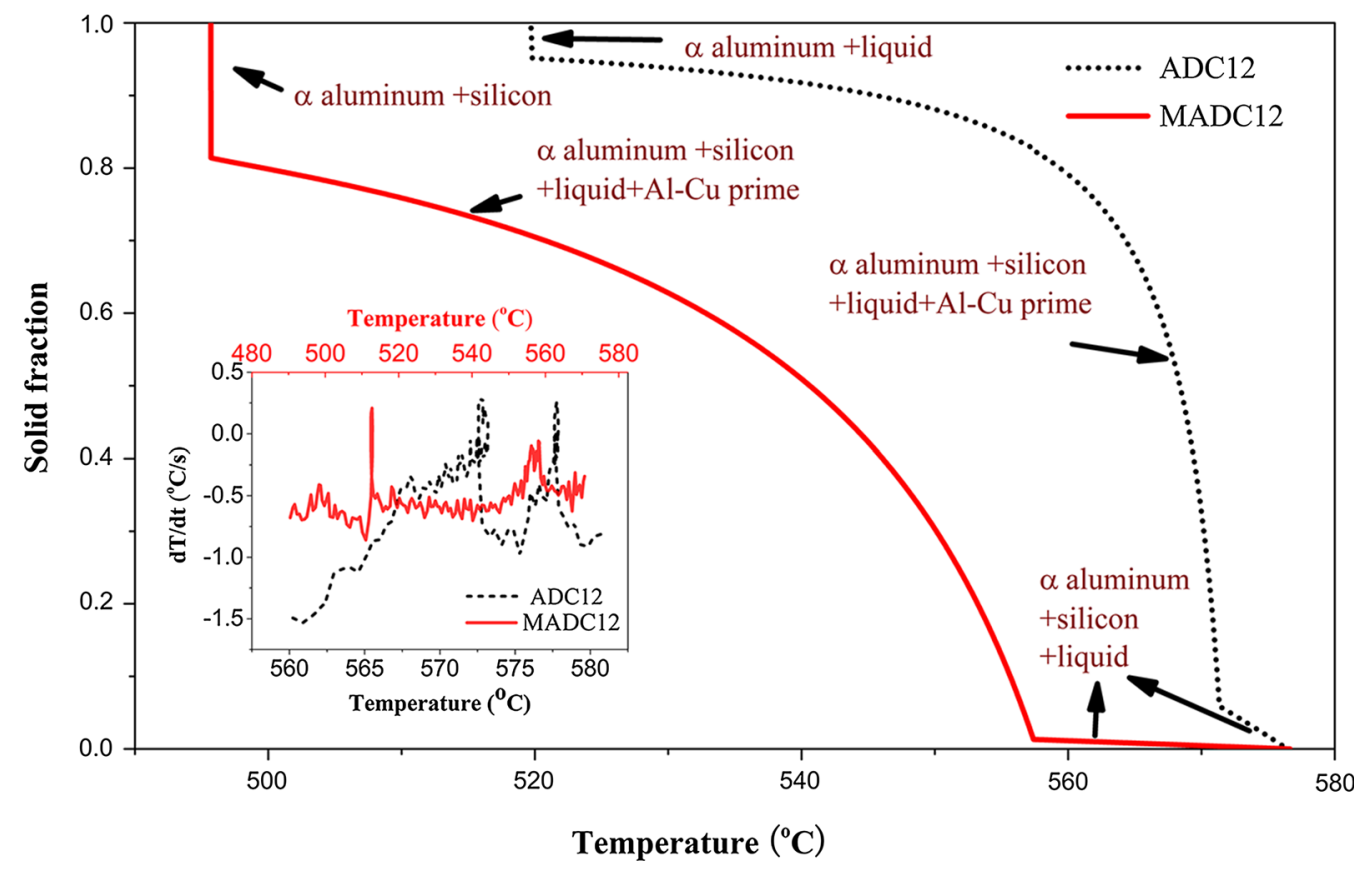

Fig. 1-Solid fraction $v$ s temperature for MADC12 and ADC12 alloys, calculated using the Thermo-Calc ${ }^{\circledR}$ Scheil solidification module. The inset shows the cooling curves of the bulk samples being cooled at $0.5^{\circ} \mathrm{C} / \mathrm{s}$, with the lower $X$-axis indicating the temperatures for ADC12 alloy and the upper $X$-axis for MADC12 alloy.

window is mounted on a custom-made mechanical rig for the semi-solid compression experiments. Details of the set-up can be found in. References 27 and 41 . The mechanical rig used was specifically designed to conduct in situ deformation and has high precision loading control (as low as $100 \mathrm{~nm} / \mathrm{s}$ ) and force measurement (least count $0.1 \mathrm{~N}$ ). A schematic of the experimental setup is shown in Figure 2. The specimen was placed at the center of alumina shackles as shown in Figure 2. A preload of approximately $7 \mathrm{~N}$ was applied to hold the sample in place during compression experiments. The loading ram was adjusted to maintain the preload during the experiment to account for thermal expansion during heating. The thermal cycle followed during the experimentation along with the sample arrangement is presented in Figure 2. A loading rate of $5 \mu \mathrm{m} / \mathrm{s}$ and the solid fraction of $75 \pm 5$ pct were maintained during the compression experiments. The fraction of solid was determined by the temperature from Scheil modeling as well as from the in situ images.

\section{Data Acquisition and Image Processing}

A monochromatic X-ray beam with an energy of $53 \mathrm{keV}$ was used in the experiment. During the deformation, a set of 38 tomograms were acquired using a PCO. Edge camera coupled with I12's camera module 3, which corresponds to a field of view of $8 \mathrm{~mm} \times$ $6 \mathrm{~mm} \cdot{ }^{[40]}$ A total of 600 projections were taken for every $180^{\circ}$ rotation of the sample for each tomogram, obtaining a voxel size of $3.2 \mu \mathrm{m}$. The exposure time was $32 \mathrm{~ms}$ per projection, with the total time of each scan

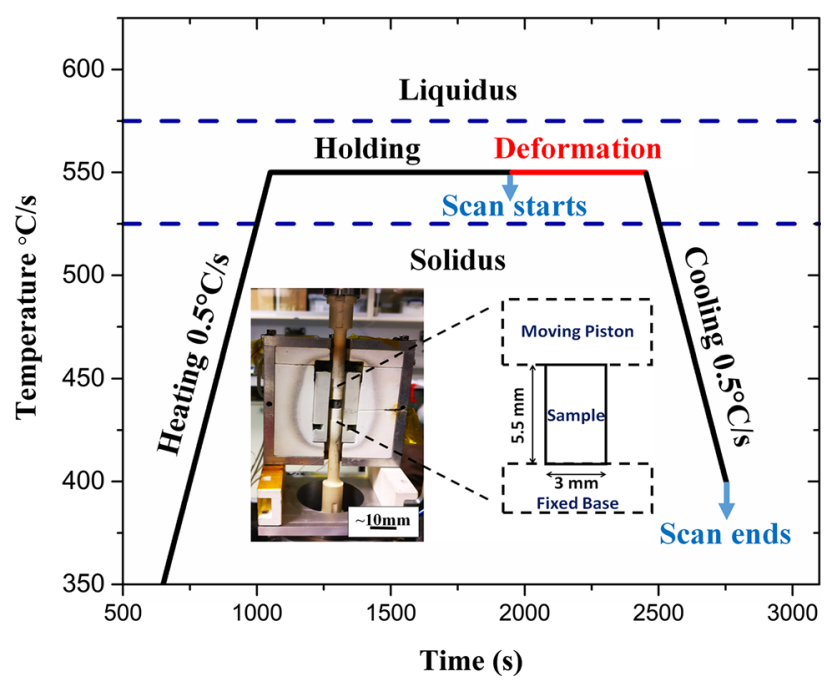

Fig. 2-Thermal cycle followed during the semi-solid compression test. The inset shows the sample mounted inside the furnace.

being $19.2 \mathrm{~s}$. Each scan was taken continuously without any additional sample rotation, which allowed for the continuous data collection. The $3 \mathrm{D}$ scan was reconstructed using filtered back-projection to produce an $1885 \times 1885 \times 2149$ voxel volume. The image was filtered using anisotropic and 3D median filters to remove noises. The filtered image was segmented using trainable weka segmentation plugin ${ }^{[42]}$ in Fiji ImageJ, ${ }^{[43]}$ which makes use of machine learning tools. 


\section{RESULTS AND DISCUSSIONS}

The transverse slices of the MADC12 sample at an approximate height of $600 \mu \mathrm{m}$ from the bottom slice and at 6 different strain values are shown in Figure 3(a) through (f). In the figure, dark gray represents the porosity and lighter gray indicates the inter-dendritic liquid, while the intermediate gray color corresponds to the primary solid phase. The longitudinal strain values indicated were measured by dividing the instantaneous length of the sample by the initial length. The sequence of the mechanisms leading to the formation of a crack is described as follows.

\section{A. Formation of Liquid Channels}

The inter-dendritic liquid, which was distributed uniformly ( $25 \pm 5$ pct) (Figure 3(a)) before the compression commenced, formed several isolated liquid channels on the application of compression load (one such channel at $\varepsilon=21.4$ pct is marked in Figure 3(b)). The measured values of liquid fraction at different strains along the loading axis (Figure 4(a)) shows the localization of liquid channels in the middle of sample. Note that the height of sample for each area liquid fraction was normalized with respect to the total height of the sample at that instant of deformation. The

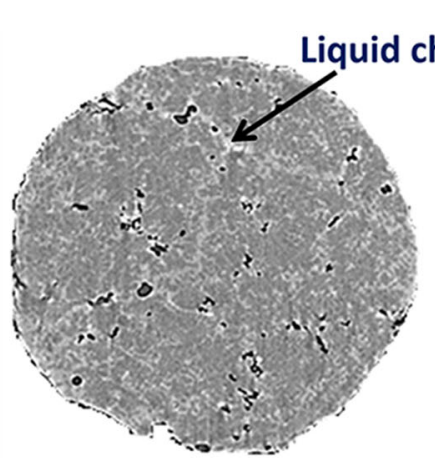

(a) $\varepsilon=21.4 \%$

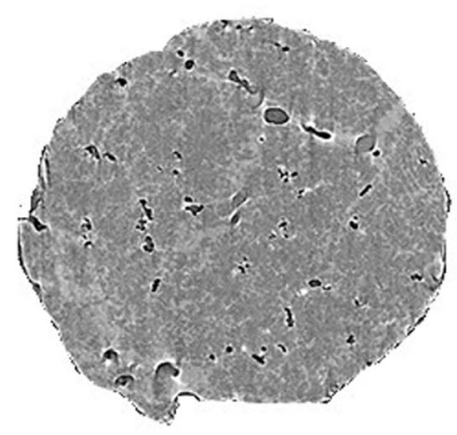

(c) $\varepsilon=32.1 \%$

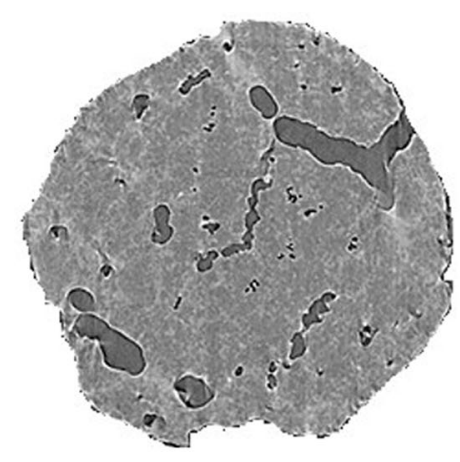

(e) $\varepsilon=39.28 \%$
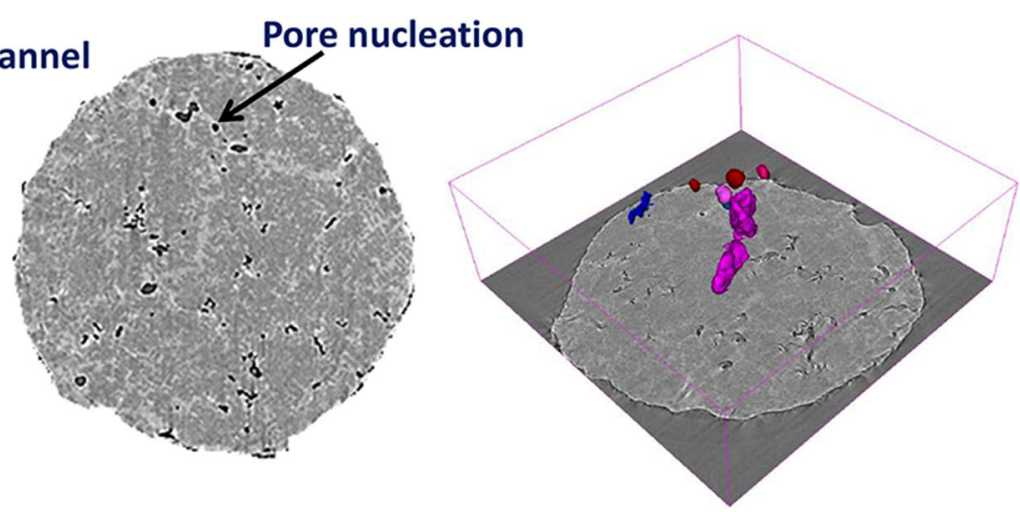

(b) $\varepsilon=25 \%$

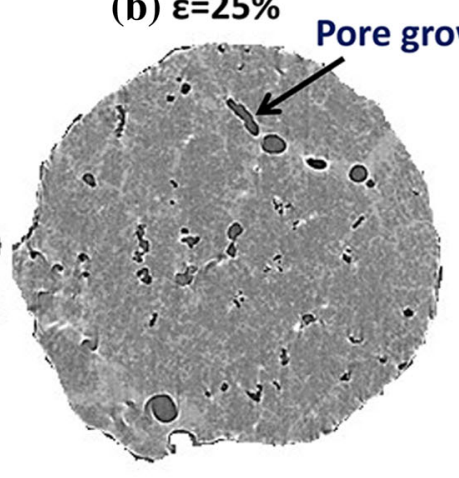

(d) $\varepsilon=33.9 \%$

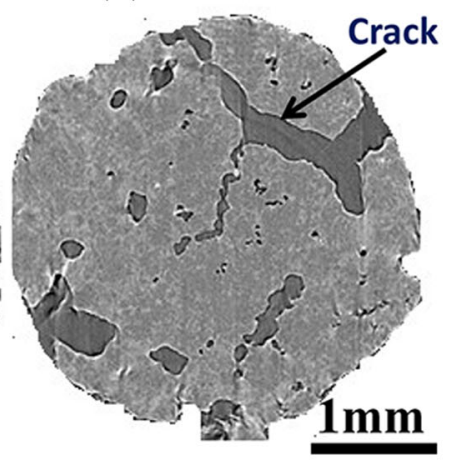

(f) $\varepsilon=50 \%$

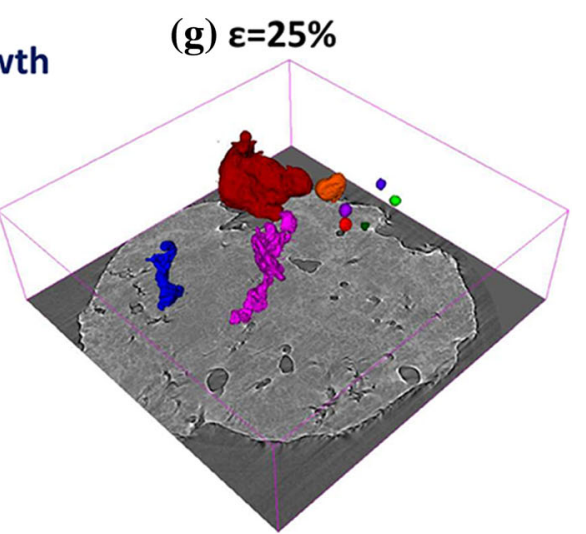

(h) $\varepsilon=39.28 \%$

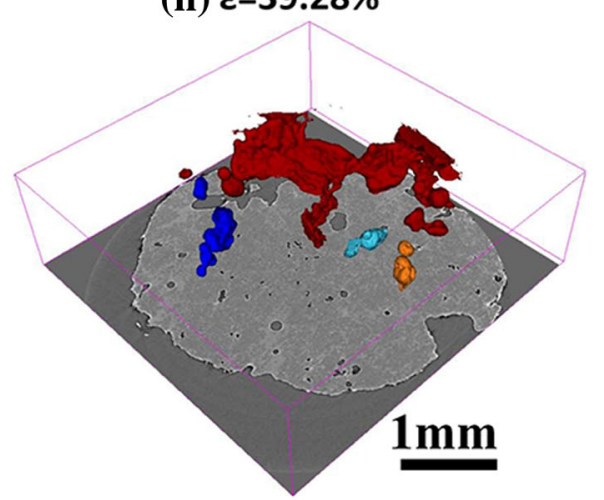

(i) $\varepsilon=50 \%$

Fig. 3- $(a-f)$ Transverse slices of the MADC12 sample (75 pct fraction solid) at a height of $\sim 600 \mu \mathrm{m}$ from the sample bottom at different strains, showing the formation and growth of gas porosity and the subsequent development of a hot tear ( $g$-i) $3 \mathrm{D}$ rendered images at equivalent time instances, with each color representing a contiguous segment of porosity. 


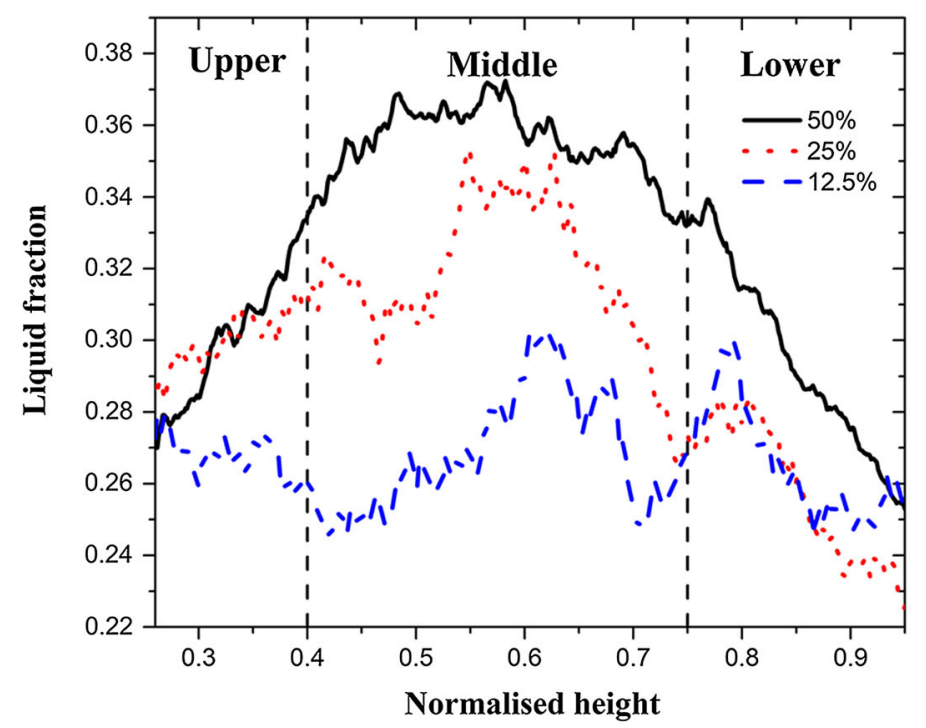

(a)

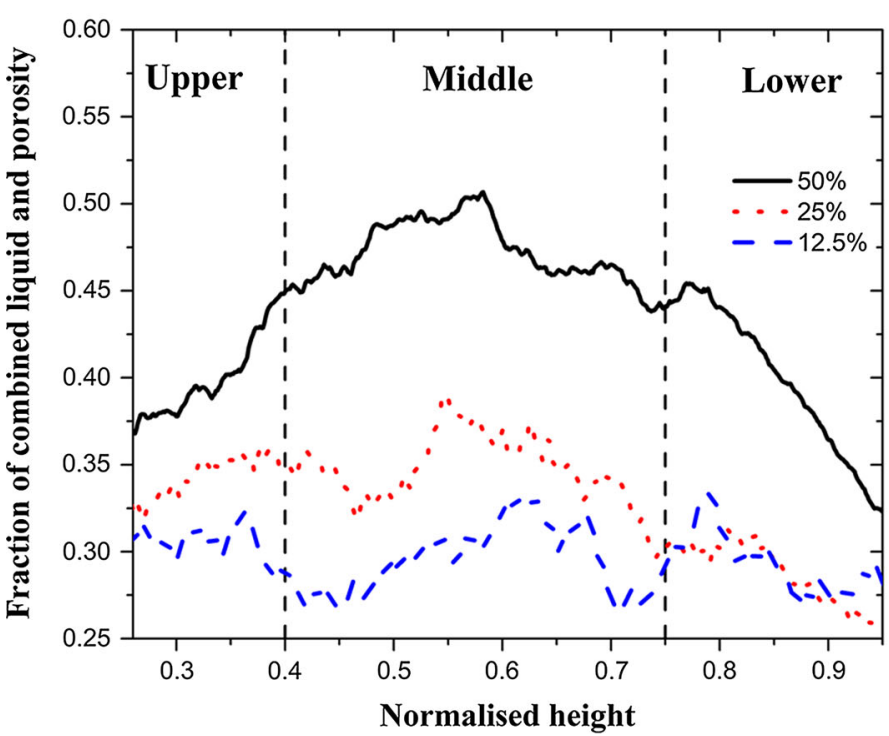

(b)

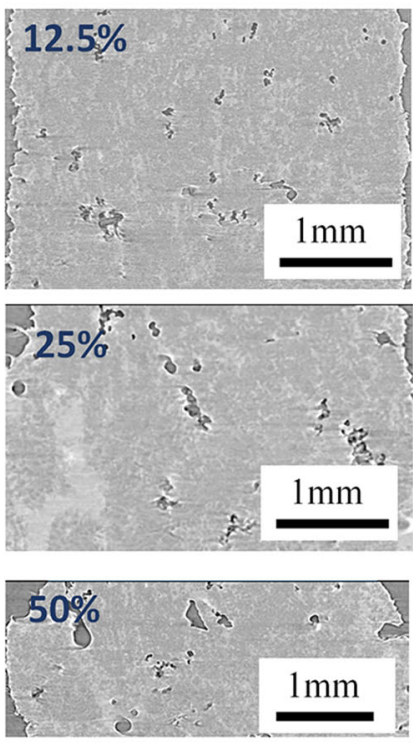

(c)

Fig. 4-Development of the (a) liquid and $(b)$ combined liquid and pore fraction along the loading axis at different strain values. (c) Longitudinal slices at different strain values showing the pore and liquid channel growth.

increase in the fraction is due to the increased area at the middle of the sample coupled with the development of liquid channels due to dilatancy. These liquid pockets were later observed to be the location of nucleation of gas micro-porosity during deformation as well as the cooling stages.

\section{B. Pore Nucleation, Growth, and Coalescence}

The nucleation of new gas pores was observed in the liquid channels at various strain values throughout the deformation stage (Figure 3(b)). The pores grew consistently while the mush deformed with expanding liquid channels. Plausibly, the feeding of the liquid resulted in a convective influx of hydrogen into the liquid pockets, thereby increasing the overall local hydrogen concentration. This is hypothesized based on the observation that the pores were predominantly spherical during the deformation regime, indicating a diffusioncontrolled gas pore growth. Furthermore, a secondary influence on pore growth was the pressure drop in the dilatant bands, which can also lead to pore volume dilation. The pores retained spherical shape until they encountered a solid (Figure 3d). The phenomenon was also observed and reported by Cai et al. ${ }^{[27]}$ who had defined different stages of dilatancy controlled shrinkage growth, which eventually led to cracking. The values of combined area of liquid fraction and porosity at different strains along the loading axis were determined and shown in Figure 4(b). By comparing Figures 4(a) and $4(\mathrm{~b})$, it is clear that the pore growth due to volume dilation picks up after 25 pct strain and most of these 
voids were concentrated around the middle of the sample. Longitudinal slices shown in Figure 4(c) show the 'middle' region indicated in Figures 4(a) and (b), in which the localization of liquid channel and voids can be seen. It should be noted that, in earlier studies by Stefanescu ${ }^{[44]}$ and Khalajzadeh, ${ }^{[45]}$ a shrinkage-induced flow term was introduced and its role on shrinkage growth had been discussed. This flow term is analogous to the dilatancy-induced flow discussed in this study.

\section{Regimes of Gas Porosity Growth: (a) Deformation and (b) Solidification}

The gas pores which did not coalesce and grew independently during both deformation and solidification stages were tracked from the tomograms obtained from the in situ experiments. The radius of these isolated pores at various strain values were measured, normalized, and data of two typical pores are represented in Figure 5 for the MADC12 alloy. The details of normalizing are provided in Supplementary Material 1 (refer to the Electronic Supplementary Material). It is evident that the growth behavior of the pores altered noticeably at the end of the deformation (when the cooling initiated). Based on the experimental observations, two regimes of pore growth were defined, namely, (a) deformation induced and (b) solidification controlled.

Recently, Sun et al., modeled the diffusion-controlled gas pore growth in aluminum melt using a Gaussian distribution function. ${ }^{[37]}$ Following their work, the pore growth in two regimes of the present data was fit using a Gaussian distribution function as given in Eq. [1].

$$
r=\frac{A}{t_{\mathrm{SD}} \times \sqrt{2 \pi}} \times \exp \left(-2 \frac{\left(t-t_{\text {mean }}\right)^{2}}{t_{\mathrm{SD}}^{2}}\right)
$$

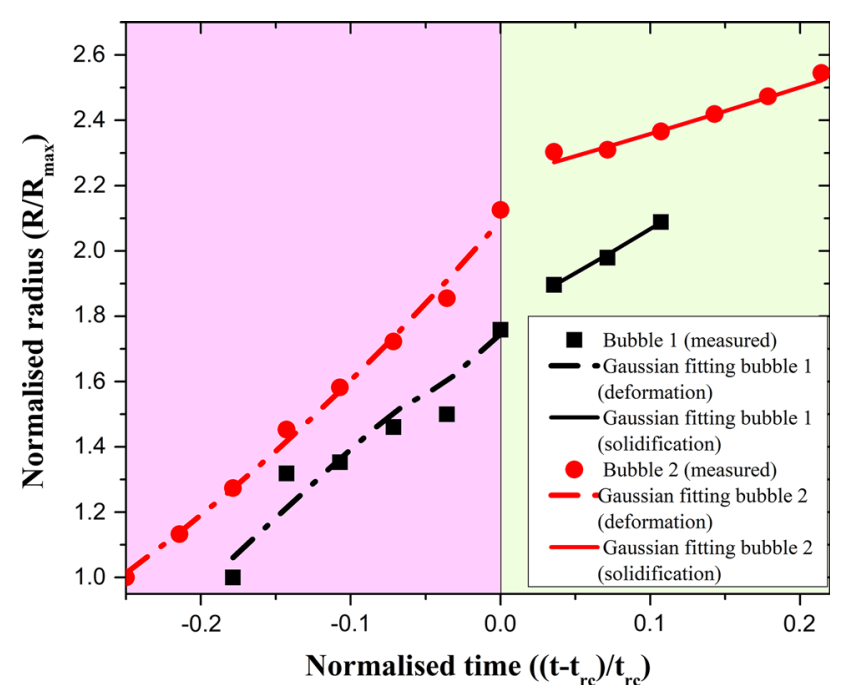

Fig. 5-Evolution of the gas micro-porosity with time during deformation and cooling (solidification) stages for MADC12 alloy. Here $R_{\max }$ and $t_{\mathrm{rc}}$ represents the maximum radius (end of solidification) and time instant at which the regime changes, respectively. where $A$ is a constant corresponding to the amplitude of the Gaussian distribution, and $t_{\text {mean }}$ and $t_{\mathrm{SD}}$ are mean and standard deviation of the Gaussian function. The fitted curves are shown with the experimental observations in Figures 5 and 6 and the adjusted $R^{2}$ value indicates a reasonably good fit.

The proposed hypothesis of a combined deformation and solidification-driven hydrogen micro-porosity is represented schematically in Figure 7 . The regions within the circles essentially show a representative elementary volume (REV) surrounding a gas pore. Figure 7(a) shows the deformation-driven flow of the liquid, which fed the hydrogen into the pore by convective transport, while Figure 7(b) shows the rejection of hydrogen during the solidification of neighboring solid structures.

\section{Numerical Evaluation of Advective Hydrogen Influx}

Since the isolated pores show a distinct growth behavior during deformation as compared to solidification, an understanding of amount of hydrogen influx carried by the liquid would be useful in correlating the flow-induced growth under different processing environments such as twin-roll casting, HPDC, etc. A calculation of 1D diffusion-driven hydrogen gas pore growth was performed using a numerical model discussed in Reference 46. It was assumed that a constant value of hydrogen concentration existed at the boundary of the domain (Figure 7), which represents the amount of hydrogen brought in by the interdendritic flow. Using the pore growth model, the necessary hydrogen concentration at the boundary that resulted in an equivalent growth obtained from the experiments was determined. Note that this analysis only accounts for the growth of the spherical pore under the influence of increased hydrogen influx due to liquid flow.

A pre-existing hydrogen gas pore of radius $R$ in liquid supersaturated with hydrogen was considered, which grows instantaneously due to diffusion of hydrogen into the pore. The size of the REV (with radius $R_{\text {domain }}$ ) was

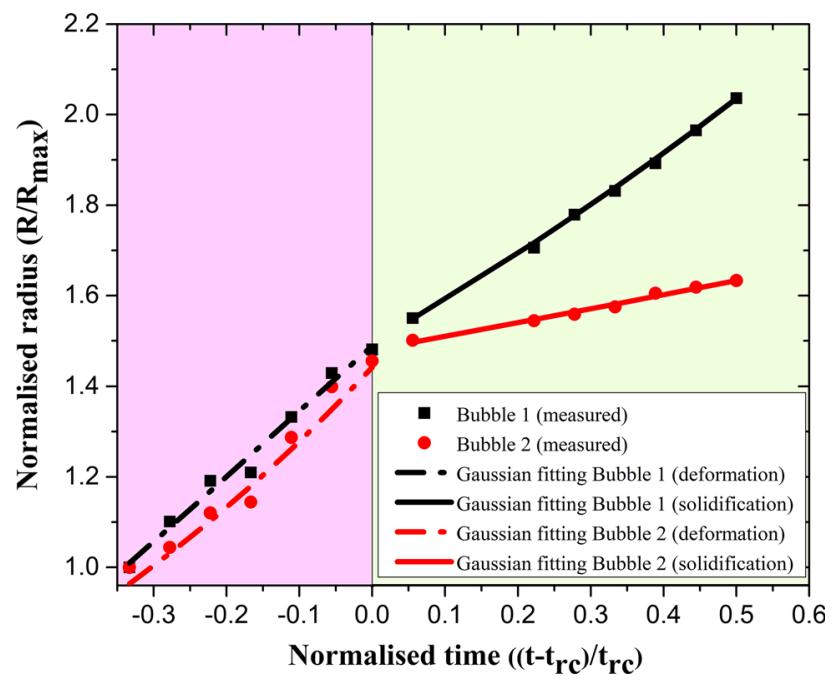

Fig. 6-Evolution of gas micro-porosity with time during deformation and cooling (solidification) stages for ADC12 alloy. 


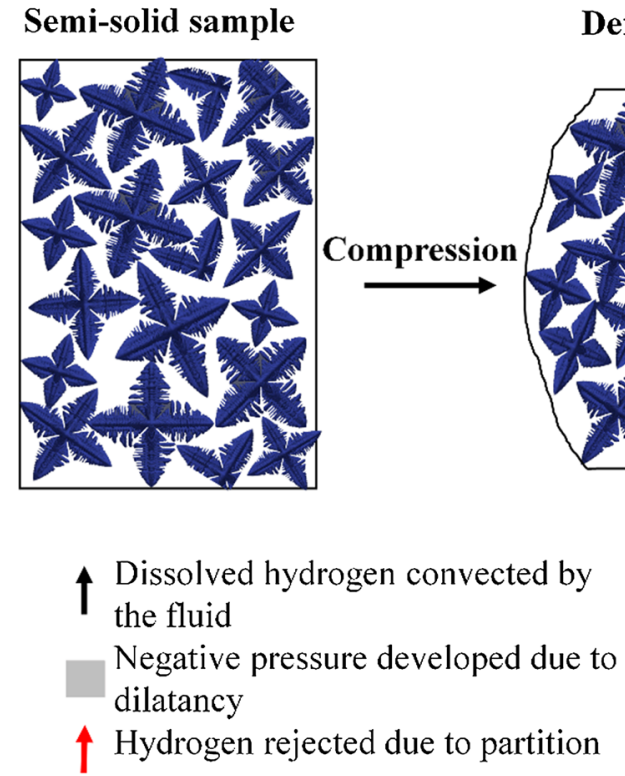

(a)
Deformed Semi-solid

sample

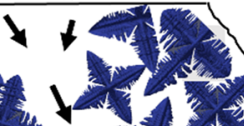

.
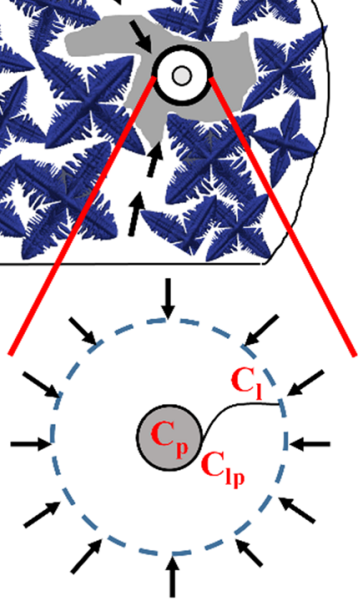

During

Solidification

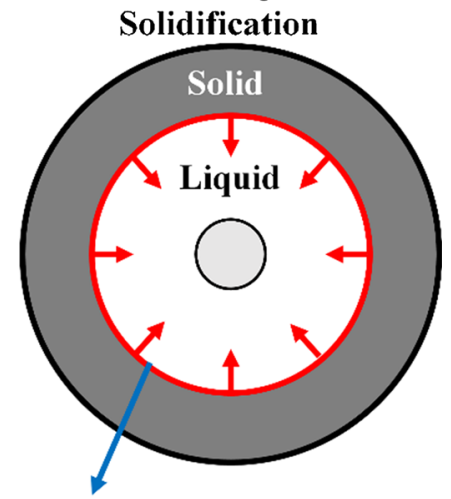

Solidifying Interface

(b)

Fig. 7-Schematic of the proposed pore growth mechanism during (a) deformation and (b) solidification. The black arrows in (a) represent the liquid flow associated with dilatancy. The black arrows in (a) and red arrows in (b) represent hydrogen flux into the representative volume around a gas pore.

assumed to be larger compared to the diffusion boundary layer. By balancing the rate of mass increase inside the pore, the influx of concentration at boundary, and the flow due to the movement of the boundary itself, the growth rate of the liquid-pore interface is evaluated as follows:

$$
V_{\text {int }}=\frac{1}{\left(C_{\mathrm{p}}-C_{\mathrm{lp}}-C_{\mathrm{d}}\right)} D_{1} \frac{\partial C_{1}}{\partial r}
$$

where $C_{1}, C_{\mathrm{p}}, C_{\mathrm{lp}}, C_{\mathrm{d}}$, are the hydrogen concentration (in $\mathrm{cc} / 100 \mathrm{~g}$ of Al) in the far field, inside the pore, at the interface, and an additional term arising due to the liquid-pore interface movement, respectively, and are functions of the pore radius and reference pressure (details in Supplementary Material 2). The details of the individual terms are given in Supplementary Material 2. $D_{1}$ is the mass diffusivity of hydrogen in aluminum. In this study, for the calculation of $C_{\mathrm{p}}$ and $C_{\mathrm{lp}}$, the reference pressure for the liquid was set at $1 \mathrm{~atm}$. The surface tension and the mass diffusivity values were taken from Sasikumar et al. ${ }^{[47]}$ and Lee et $a l^{[31,46]}$ The equivalent radius, measured from the tomographic scans, was assumed to be the initial radius of the sample. A fixed concentration input at the far-field liquid that drives the influx of hydrogen can be obtained as follows:

$$
C_{\mathrm{l}}=C_{\mathrm{lp}}+\frac{V_{\mathrm{int}}\left(C_{\mathrm{p}}-C_{\mathrm{lp}}-C_{\mathrm{d}}\right)}{D_{\mathrm{l}}} R
$$

Using the above relation, a concentration change created by the deformation-induced flow was estimated and is reported for a few pore radii in Table II.
The model was used to calculate the input concentration for a range of input radii (12.47-36.01 $\mu \mathrm{m}$ for MADC12 and 69.95-131.74 $\mu \mathrm{m}$ for ADC12) and the corresponding rate of change of the concentration at the REV interface was calculated and found to be of the order $\sim 10^{-5}$.

Using mass conservation, this rate of change of concentration at the interface is related to the convective flux given by Eq. [4]. Note that we have assumed that the velocity of the liquid flow is of the same order as the deformation rate $(V)$

$$
\frac{\partial C}{\partial t}=V \frac{\partial C}{\partial x}
$$

It can be seen that by increasing the velocity of deformation, the concentration build-up at REV increases, for a given far-field concentration. This increase in the concentration gradient between the REV boundary and the pore-liquid interface drives the pore growth. This information is helpful in evaluating flowdriven hydrogen concentration build-up and eventual porosity, particularly for high-pressure die casting environments, where flow rates are very high $(\sim 20-60 \mathrm{~m} / \mathrm{s}){ }^{[2]}$

\section{STRESS-STRAIN BEHAVIOR DURING COMPRESSION}

The occurrence of dilatancy is ascertained with the help of flow stress $v s$ strain data obtained from the experiment. The normalized stress $v s$ strain curve with the insets in the figure indicating the transverse slice at every 10 pct strain from the semi-solid compression is 
Table II. The Concentration Input at Domain Boundary Estimated from the Model

\begin{tabular}{|c|c|c|c|c|c|}
\hline \multirow[b]{2}{*}{ Alloy } & \multirow[b]{2}{*}{ Pore } & \multicolumn{2}{|c|}{ Radius of the Gas Pore $(\mu \mathrm{m})$ in the Two Regimes } & \multicolumn{2}{|c|}{ Avg. Concentration Input (cc/100 g Al) Between Two Scans } \\
\hline & & Deformation & Solidification & Deformation & Solidification \\
\hline \multirow[t]{2}{*}{ MADC12 } & 1 & 29.8 & 68.8 & $2.6 \times 10^{-4}$ & $1.9 \times 10^{-5}$ \\
\hline & 2 & 37.9 & 70.4 & $6.3 \times 10^{-4}$ & $1.5 \times 10^{-5}$ \\
\hline \multirow{2}{*}{ ADC12 } & 1 & 69.9 & 119.3 & $8.0 \times 10^{-4}$ & $1.1 \times 10^{-4}$ \\
\hline & 2 & 77.0 & 124.5 & $4.8 \times 10^{-4}$ & $5.2 \times 10^{-5}$ \\
\hline
\end{tabular}

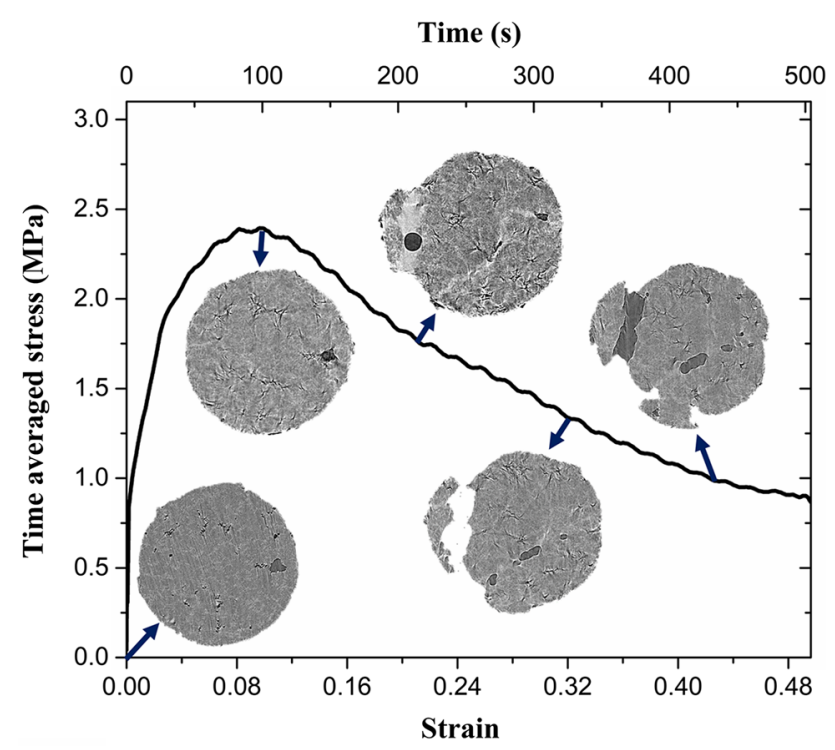

Fig. 8- Stress-strain curve for MADC12 alloy. Insets display the transverse slice of the specimen at the indicated strain values in the range of $0-50$ pct.

shown in Figure 8. Note that the stress is calculated as the ratio of the applied load to the initial sample area. The graph shows characteristic peak at a strain value of $\sim 0.1$, which indicated that the stress developed due to the pinning of the grains was being relieved by the development of liquid channels due to dilatancy (inset at 20 pet strain). Further dilation of the liquid channel and nucleation and growth of porosity resulted in a continuous decrease of the load, and eventual formation of a hot tear at around 0.32 strain.

\section{CONCLUSIONS}

Ultrafast synchrotron X-ray imaging was utilized to observe the porosity growth in two different Al-Si-Cu diecast alloy specimens at $\sim 75 \pm 5$ pct solid fraction during compression and solidification conditions. In the present work, we have proposed, a mechanism of flow-driven hydrogen pore growth which is critical for predicting final porosity in high-pressure die-cast components. The following conclusions were drawn from the study.

1. Two distinct regimes of hydrogen pore growth, namely deformation-induced flow-driven growth and solidification-controlled growth were observed and quantified. The growth rates were determined by measuring the equivalent pore radius from in situ experiments. The measured growth rate values showed a clear and abrupt change at the end of deformation regime, and were also found to agree with the trends reported in the literature using Gaussian distribution functions.

2. The role of dilatancy in deformation-induced pore growth via advective hydrogen transport was ascertained using quantification of localized liquid channels and the stress-strain behavior of the semi-solid under compressive loading.

3. The hydrogen concentration influx during deformation-induced flow that closely represents the observed experimental trend was estimated using a 1D diffusion model. This revealed a hydrogen concentration boundary condition, and can be further used to correlate flow-driven hydrogen influx for different processing routes.

\section{ACKNOWLEDGMENTS}

The authors thank the University Research Program at Ford Motor Company, USA for partial financial support. We are grateful to Diamond light source for the beamtime (EE16188-1), Dr. Sara Nonni, Dr. Nolwenn Legall, and Sebastian Marucci for their help during beamtime. S.K and P.D.L acknowledge the sanction of the project P1299 under the SPARC (Scheme for Promotion of Academic and Research Collaboration) initiative. B.C. acknowledges the support provided by the Diamond Birmingham Collaboration and Alan Turing Fellowship. The support from the ferrous metallurgy and the machine tools laboratories at IIT Bombay in preparing the samples is acknowledged.

\section{ELECTRONIC SUPPLEMENTARY MATERIAL}

The online version of this article (https://doi.org/10. 1007/s11661-019-05378-8) contains supplementary material, which is available to authorized users.

\section{REFERENCES}

1. PKM Jason: Rowe: Advanced Materials in Automotive Engineering, 1st ed., Woodhead Publishing Limited, Cambridge, 2012. 
2. SH Huo, M Qian, GB Schaffer, and E Crossin: Fundamentals of Aluminium Metallurgy, Woodhead Publishing, Cambridge, 2011.

3. DG Eskin, Suyitno, and L Katgerman: Prog. Mater. Sci., 2004, vol. 49, pp. 629-711.

4. C Puncreobutr, PD Lee, KM Kareh, T Connolley, JL Fife, and AB Phillion: Acta Mater., 2014, vol. 68, pp. 42-51.

5. CM Gourlay, AK Dahle, and HI Laukli: Metall. Mater. Trans. A, 2004, vol. 35A, pp. 2881-91.

6. P Rousset, M Rappaz, and B Hannart: Metall. Mater. Trans. A, 1995, vol. 26A, pp. 2349-58.

7. N Shevchenko, S Boden, G Gerbeth, and S Eckert: Metall. Mater. Trans. A, 2013, vol. 44A, pp. 3797-808.

8. PD Lee and JD Hunt: Acta Mater., 2001, vol. 49, pp. 1383-98.

9. RC Atwood, S Sridhar, W Zhang, and PD Lee: Acta Mater., 2000, vol. 48, pp. 405-17.

10. SG Lee, AM Gokhale, GR Patel, and M Evans: Mater. Sci. Eng. $A, 2006$, vol. 427, pp. 99-111.

11. SG Lee and AM Gokhale: Scr. Mater., 2006, vol. 55, pp. 387-90.

12. X Li, SM Xiong, and Z Guo: Mater. Sci. Eng. A, 2015, vol. 633, pp. $35-41$.

13. G Lesoult, CA Gandin, and NT Niane: Acta Mater., 2003, vol. 51, pp. 5263-83.

14. A Zavaliangos: Int. J. Mech. Sci., 1998, vol. 40, pp. 1029-41.

15. CM Gourlay, HI Laukli, and AK Dahle: Metall. Mater. Trans. A, 2007, vol. 38A, pp. 11-16.

16. KM Kareh, C O'Sullivan, T Nagira, H Yasuda, and CM Gourlay: Acta Mater., 2017, vol. 125, pp. 187-95.

17. M Sistaninia, S Terzi, AB Phillion, JM Drezet, and M Rappaz: Acta Mater., 2013, vol. 61, pp. 3831-41.

18. E Tzimas and A Zavaliangos: Acta Mater., 1999, vol. 47, pp. 517-28.

19. S Terzi, L Salvo, M Suéry, N Limodin, J Adrien, E Maire, Y Pannier, M Bornert, D Bernard, M Felberbaum, M Rappaz, and E Boller: Scr. Mater., 2009, vol. 61, pp. 449-52.

20. CM Gourlay and AK Dahle: Nature, 2007, vol. 445, pp. 70-73.

21. WY Kim, CG Kang, and BM Kim: J. Mater. Process. Technol., 2007, vol. 191, pp. 372-76.

22. CG Kang, JS Choi, and KH Kim: J. Mater. Process. Technol., 1999, vol. 88, pp. 159-68.

23. P Kapranos, TY Liu, HV Atkinson, and DH Kirkwood: J. Mater. Process. Technol., 2001, vol. 111, pp. 31-36.

24. S Karagadde, PD Lee, B Cai, JL Fife, MA Azeem, KM Kareh, C Puncreobutr, D Tsivoulas, T Connolley, and RC Atwood: Nat. Commun., 2015, https://doi.org/10.1038/ncomms9300.

25. E Guo, AB Phillion, B Cai, S Shuai, D Kazantsev, T Jing, and PD Lee: Acta Mater., 2017, vol. 123, pp. 373-82.

26. KM Kareh, PD Lee, RC Atwood, T Connolley, and CM Gourlay: Nat Commun, 2014, https://doi.org/10.1038/ncomms5464.
27. B Cai, S Karagadde, L Yuan, TJ Marrow, T Connolley, and PD Lee: Acta Mater., 2014, vol. 76, pp. 371-80.

28. M Rappaz, JM Drezet, and M Gremaud: Metall. Mater. Trans. A, 1999, vol. 30A, pp. 449-55.

29. M Sistaninia, AB Phillion, JM Drezet, and M Rappaz: Metall. Mater. Trans. A, 2011, vol. 42A, pp. 239-48.

30. F Bonollo, N Gramegna, and G Timelli: JOM, 2015, vol. 67, pp. 901-8.

31. PD Lee and JD Hunt: Acta Mater., 1997, vol. 45, pp. 4155-69.

32. RH Mathiesen, L Arnberg, F Mo, T Weitkamp, and A Snigirev: Phys. Rev. Lett., 1999, vol. 83, pp. 5062-65.

33. H Liao, W Song, Q Wang, L Zhao, and R Fan: JOM, 2012, vol. 64, pp. 22-27.

34. L Zhao LieHengcheng: China Foundry, 2011, vol. 8, pp. 14-18.

35. AV Catalina, DM Stefanescu, S Sen, and WF Kaukler: Metall. Mater. Trans. A., 2004, vol. 35A, pp. 1525-38.

36. H Yin and JN Koster: Isij Int., 2000, vol. 40, pp. 364-72.

37. S Sun, Q Hu, W Lu, Z Ding, M Xia, and J Li: Metall. Mater. Trans. A, 2018, vol. 49A, pp. 4429-34.

38. X Li, Z Guo, and S Xiong: Mater. Charact., 2017, vol. 129, pp. 344-52.

39. BS Andersson, T Helander, L Hdghmd, and P Shi: Coupling Phase Diagr. Thermochem., 2002, vol. 26, pp. 273-312.

40. M Drakopoulos, T Connolley, C Reinhard, R Atwood, O Magdysyuk, N Vo, M Hart, L Connor, B Humphreys, G Howell, S Davies, T Hill, G Wilkin, U Pedersen, A Foster, N De Maio, M Basham, F Yuan, and K Wanelik: J. Synchrotron Radiat., 2015, vol. 22, pp. 828-38.

41. B Cai, PD Lee, S Karagadde, TJ Marrow, and T Connolley: Acta Mater., 2016, vol. 105, pp. 338-46.

42. I Arganda-Carreras, V Kaynig, C Rueden, KW Eliceiri, J Schindelin, A Cardona, and HS Seung: Bioinformatics, 2017, vol. 33, pp. 2424-26.

43. J Schindelin, I Arganda-Carreras, E Frise, V Kaynig, M Longair, T Pietzsch, S Preibisch, C Rueden, S Saalfeld, B Schmid, JY Tinevez, DJ White, V Hartenstein, K Eliceiri, P Tomancak, and A Cardona: Nat. Methods, 2012, vol. 9, pp. 676-82.

44. DM Stefanescu and AV Catalina: Int. J. Cast Met. Res., 2011, vol. 24, pp. 144-50.

45. V Khalajzadeh, KD Carlson, DG Backman, and C Beckermann: Metall. Mater. Trans. A, 2017, vol. 48A, pp. 1797-16.

46. S Karagadde and P Dutta: Int. Commun. Heat Mass Transf., 2016, vol. 79, pp. 16-20.

47. R Sasikumar, MJ Walker, S Savithri, and S Sundarraj: Model. Simul. Mater. Sci. Eng., 2008, https://doi.org/10.1088/0965-0393/ $16 / 3 / 035009$

Publisher's Note Springer Nature remains neutral with regard to jurisdictional claims in published maps and institutional affiliations. 